\title{
TEORÍA DEL CEREBRO TOTAL: PLENA VIGENCIA PARA EL PROCESO DE ENSEÑANZA-APRENDIZAJE ACTUAL
}

\author{
WHOLE BRAIN THINKING SYSTEM: FULL VALIDITY FOR \\ THE CURRENT TEACHING-LEARNING PROCESS
}

\author{
ANDREY SINDEEV \\ Universidad Norbert Wiener
}

\section{RESUMEN}

La Neurociencia representa la integración teórico-práctica de todas las disciplinas relacionadas con la actividad humana-como la psicología, la pedagogía, la lingüística, la antropología, la filosofía, la política, la cibernética, la inteligencia artificial y otras-, fundamentalmente porque la conducta humana es la manifestación de los procesos mentales, que a su vez se producen por los procesos cerebrales. Y los docentes no podemos ni debemos ser ajenos a este campo del saber. Las investigaciones neurocientíficas generan el material teórico para la práctica educativa. Un mayor conocimiento de las bases neurofisiológicas del Sistema Nervioso Central ayuda a encontrar los mecanismos de mejora del aprendizaje para su posterior transformación en teorías, paradigmas, corrientes y estrategias didácticas del nuevo milenio. Una de las teorías neurocientíficas clásicas en plena vigencia que ha demostrado su utilidad práctica en el ámbito educativo -combinada con la facilidad de aplicación e interpretación- es la teoría del Cerebro Total, de Herrmann. Esta teoría conceptualiza al cerebro como el órgano dividido en partes, e integrado en un todo al mismo tiempo, que permite entender mejor el comportamiento humano y modificarlo de una manera óptima. Asimismo, existen instrumentos de evaluación que permiten realizar el diagnóstico respectivo y determinar los estilos de pensamiento de los estudiantes. El docente necesita de descubrimientos neurocientíficos para mejorar su comprensión del proceso de aprendizaje, perfeccionar sus capacidades de enseñanza mediante nuevas estrategias, y dejar de lado las prácticas inadecuadas, antieducativas $\mathrm{y}$ tradicionales que hasta hoy afectan al sistema educativo.

Palabras clave: Neurociencia, teoría del Cerebro Total, dominancia de cuadrantes cerebrales, enseńanza-aprendizaje.

\section{ABSTRACT}

Neuroscience represents the theoretical-practical integration of all disciplines that have to do with human activity, such as psychology, pedagogy, linguistics, anthropology, philosophy, politics, cybernetics, artificial intelligence, etc. because human behavior is the manifestation of mental processes that in turn are produced by brain processes. The teachers cannot and should not be outside this field of knowledge. Neuroscientific research generates the material for educational theory and practice. The greater knowledge of the neurophysiological bases of the Central Nervous System helps to find the mechanisms to improve the learning for its later transformation in theories, paradigms, currents and didactic strategies of the new millennium. One of the classic neuroscientific theories in full force that has 
demonstrated its practical utility in the educational field-combined with the ease of application and interpretation - is Herrmann's Whole Brain Thinking System. This theory conceptualizes the brain as the organ divided into parts and integrated into a whole at the same time allowing a better understanding of human behavior and modifying it in an optimal way. In addition, there are evaluation instruments that allow a respective diagnosis and determine the thinking styles of students. The teacher needs neuroscientific discoveries to improve their understanding of the learning process to improve their teaching abilities through new strategies, abandoning the inadequate, anti-educational and traditional practices that hitherto affect the education system.

Key words: Neuroscience, Whole Brain Thinking System, Brain Dominance Quadrants, Teaching-Learning.

\section{INTRODUCCIÓN}

El mundo de hoy es un mundo de cambios constantes cuya escala, alcance y ritmo no tienen precedentes. El crecimiento y globalización de los mercados, la diferenciación de las poblaciones, la migración y movilidad geográfica crecientes, las redes de comunicación y sistemas de información, así como la consolidación de una sociedad globalizada, son solo algunos de los factores de los cambios sociodemográficos y económicos actuales.

Sin embargo, según el Informe Mundial sobre el Aprendizaje y la Educación de Adultos de la Unesco (2010), para millones de personas estos cambios han significado más limitaciones que oportunidades. Muchas de ellas luchan contra la pobreza, la discriminación, el hambre, la inequidad. Vistos integralmente, los trastornos sociales abarcan todo el horizonte. Entre otros factores, sostiene que la educación de adultos representa una pieza de vital importancia para realizar cambios sociales. Se requiere una voluntad política y recursos suficientes para que la educación de adultos pueda ayudar a las personas a romper el ciclo de explotación y encaminarse hacia un futuro sostenible.
Por otro lado, la Guía para el Desarrollo del Pensamiento Crítico (2006), elaborada por el Ministerio de Educación del Perú, reconoce que por años se ha privilegiado solo el uso de las capacidades cognitivas, generalmente ejercidas por el hemisferio cerebral izquierdo, es decir el pensamiento racional, lógico y formal, cuando en realidad la creatividad, la emotividad y la intuición no se estimulan o se estimulan muy poco. En el mismo sentido, Gómez (2004) enfatiza que a pesar de la existencia de diferentes modalidades de pensamiento y, consecuentemente, de aprendizaje, los sistemas educativos de las sociedades occidentales, en su mayoría, privilegian algunos de ellos. Por ejemplo, la lectura, la escritura y la aritmética claramente apuntan al desarrollo del hemisferio izquierdo, tendencia que es evidente al revisar los contenidos curriculares; y se limita la otra mitad del cerebro. El desarrollo cerebral en el área lógico-verbal no implica necesariamente su superioridad en otras dimensiones, como la visoespacial, corporal, musical, intra o interpersonal. En este caso, el hincapié del sistema educativo en el desarrollo lógico-verbal se presenta como un error que limita el desarrollo de otras capacidades. Además, no todos los individuos están orientados hacia un procesamiento verbal de la información. 
Como es lógico, el aprendizaje de cualquier contenido será más efectivo si se utilizan las estrategias que estimulen la actividad de ambos hemisferios de manera adecuada y sostenida.

En consecuencia, podemos elevar la efectividad del aprendizaje utilizando tanto los contenidos verbales tradicionales como las estrategias no verbales o figurativas (gráfica, pictórica u otra). Adicionalmente, es importante considerar los factores cognitivos y motivacionales como una totalidad. Si el estudiante percibe el ambiente educativo como amenazante, hostil o inseguro, en lugar de excitante, estimulante o retador, su aprendizaje no va a ser el esperado. Aquí estamos yendo más allá de la corteza cerebral, involucrando las áreas subcorticales, cuyo papel en el desarrollo de la personalidad es mucho mayor de lo que se ha pensado.

Por tanto, es indispensable reconocer los diferentes estilos o tipos de procesamiento de información, incluyendo el aprendizaje, para reforzar y desarrollar diferentes modos de enseñanza, en particular, en los discentes adultos. Además, cada persona debe ser consciente de su propio dominio cognitivo para poder desarrollarlo y utilizarlo durante su vida.

Los descubrimientos neurocientíficos de las últimas décadas constantemente motivan a los educadores a mejorar el rendimiento de sus alumnos por medio de nuevas técnicas y procedimientos de enseñanza. El adelanto norteamericano en esta área ha sido adaptado y se aplica en otros países. Los intentos de sistematizar y analizar los resultados de la aplicación práctica de la teoría de la Dominancia Cerebral (Cerebro Total) en diferentes ámbitos educativos Están vigentes en el contexto latinoamericano.

\section{NEUROCIENCIA EN EL CONTEX- TO EDUCATIVO}

Salas (2003) hace un llamado a los docentes a tomar conciencia de la necesidad de conocer cuál es la estructura y funcionamiento del cerebro, y considerarlo de suma importancia para el desarrollo del proceso de enseñanza-aprendizaje más acorde con las características psicofisiológicas innatas del cerebro para aprender. El autor se refiere a la pregunta de Sylwester: «¿Puede una profesión encargada de desarrollar un cerebro efectivo y eficiente permanecer desinformada con respecto al cerebro?» (2003, p.167).

La Neurociencia no es una rama de la Medicina, tampoco se reduce solamente al campo de las ciencias de la salud, aunque las ciencias naturales -como la anatomía, la biología molecular y celular, la genética, la bioquímica, la fisiología, la neurología, la neurocirugía, la neuropsicología, la neuroinmunología, etc.- generan los conocimientos básicos para su desarrollo. La Neurociencia representa la integración teórico-práctica de todas las disciplinas que tienen que ver con la actividad humana, como la psicología, la pedagogía, la lingüística, la antropología, la filosofía, la política, la cibernética, la inteligencia artificial, etc., debido a que la conducta humana es la manifestación de los procesos mentales que a su vez se producen por los procesos cerebrales. Y los docentes no podemos ni debemos estar ajenos a este campo del saber.

De Aparicio (2009) generaliza bajo el concepto de neurociencias a todas las especialidades que abordan el estudio del sistema nervioso. Considerando la gran complejidad de este sistema y su rol en todos los aspectos de la actividad humana, evidentemente se requieren múltiples 
disciplinas para su estudio. ¿Cómo conectamos la Psicobiología, que estudia la relación entre el cerebro y el comportamiento, con la Psicopedagogía, que se basa en la relación entre el cerebro y la educación? Desde luego, los profesionales de diversas disciplinas, tales como biólogos, médicos, genetistas, bioquímicos, filósofos, educadores, psicólogos, tienen que manejar los mismos términos al respecto del sistema nervioso y su funcionamiento. Así, la tendencia es hacia la conceptualización de una sola neurociencia y la construcción de una teoría global que conecte procesos cerebrales con procesos mentales y sus manifestaciones conductuales.

Maureira (2010) considera que lo principal para un educador es comprehender a la Neurociencia como una manera de concebir al cerebro integralmente, desde su estructura hasta los procesos de registro y conservación de la información, para utilizar luego este conocimiento en experiencias educativas en el aula.

En este mismo orden y dirección, Francis (2005) explica que la construcción del conocimiento en un acto educativo se basa en la comunicación, percepción, interpretación, elaboración y representación del sujeto. A los efectos de esta apreciación se puede concluir que la cantidad de construcciones mentales es igual al número de personas que participaron en el acto educativo. Significa entonces que el acto pedagógico debe basarse en la actividad del alumno. Además, nos hace recordar que la actividad mental interactúa con el ámbito cultural, reestructurando al ser humano.

El principal propósito de las neurociencias, estrechamente ligado a la educación, es aclarar los mecanismos de cómo las células nerviosas individuales compuestas por las moléculas bioquímicas universales pueden producir las conductas singulares, interactuando con otros individuos y el medio ambiente (Jessel et al. 1997, citados por De la Barrera y Donolo 2009).

Desde luego, la tarea no es fácil. El cerebro es el órgano más complejo del ser humano y, para muchos, la realidad más compleja del universo (Martínez 1987, Martínez 1992, Martínez 1993, citados por De Aparicio 2009; Castro 2012).

La interrogante relacionada con el dualismo conceptual cerebro-mente están lejos de resolverse y el funcionamiento cerebral guarda todavía muchos misterios. Además, la información proveniente de las investigaciones neurocientíficas es muy diversa, compleja y cambiante, lo que dificulta la actualización en el tema. Los profesores, atareados por sus propias materias, se encuentran perdidos en el océano informacional neurocientífico. Es importante proporcionar las "cartas neuronáuticas" para facilitar el proceso de "neuronavegación”.

\section{LA TEORÍA DE CUADRANTES CEREBRALES O CEREBRO TOTAL}

Una de las teorías neurocientíficas clásicas que ha demostrado su utilidad práctica en el ámbito educativo -combinada con la facilidad de aplicación e interpretación- es la teoría del Cerebro Total de Herrmann. El constructo se basa en las teorías previas de Sperry y de MacLean, que formularon un modelo que integra el neocortex (hemisferios) con el sistema límbico. Esta unión se presenta como una integridad orgánica y funcional compuesta por cuatro cuadrantes, cuyas interacciones permiten la compleja operatividad del cerebro, incluyendo procesos de creatividad y aprendizaje (Gardié 2000). 
Estos son los cuadrantes:

El lóbulo superior izquierdo (cuadrante A): hemisferio izquierdo, Cortical Izquierdo (CI).

El lóbulo inferior izquierdo (cuadrante B): sistema límbico, parte izquierda, Límbico Izquierdo (LI).

El lóbulo inferior derecho (cuadrante C): sistema límbico, parte derecha, Límbico Derecho (LD)

El lóbulo superior derecho (cuadrante D): hemisferio derecho, Cortical Derecho (CD).

Consecuentemente, se deduce la existencia de cuatro estilos de pensamiento característicos para cada cuadrante (A, B, C y D). Son cuatro modalidades independientes para procesar información, operar, pensar, crear, aprender y convivir con el mundo, que pueden realizarse en forma individual o de manera combinada (secuencial o simultánea), en los diferentes procesos del funcionamiento cerebral:

Cuadrante A (CI): estilo de pensamiento lógico, cuantitativo, analítico, crítico, matemático, realista.

Cuadrante B (LI): estilo de pensamiento conservador, organizado, secuencial, detallado, planificado y controlado.

Cuadrante C (LD): estilo de pensamiento comunicativo, emocional, expresivo, empático, humanístico, sensorial, interpersonal, simbólico, musical y espiritual.

Cuadrante D (CD): estilo de pensamiento global, idealista, intuitivo, conceptual, holístico, simultáneo, integrador, creativo, sintético, imaginativo, visual, artístico, espacial y metafórico.
Herrmann utilizó su modelo aplicando una encuesta a una muestra de 100000 personas en los EE.UU. El cuestionario estuvo formado por ítems que representaron las funciones cerebrales diferentes, utilizadas comúnmente en situaciones de la vida diaria, laboral, actividades académicas o de recreación. De acuerdo a las respuestas se detectó la tendencia en la dominancia cerebral correspondiente a cada cuadrante.

Los hallazgos permitieron a Herrmann afirmar que el $6 \%$ de las personas tiene una dominancia simple (de uno de los cuatro cuadrantes); el $60 \%$ tiene una dominancia doble con diferentes combinaciones ( $\mathrm{AB}$; $\mathrm{CD}$; $\mathrm{AD}$; $\mathrm{AC}$ y $\mathrm{BC}$ ). El $30 \%$ tiene una dominancia triple (de tres cuadrantes en diferentes combinaciones); $y$ solo el $4 \%$ tiene una dominancia cuádruple. Entonces, el $94 \%$, aproximadamente, tiene dominancia en más de un cuadrante cerebral (Gómez 2004).

Cuantitativamente se puede medir la dominancia mediante el Diagnóstico Integral de Dominancia Cerebral de Gardié (Gardié 2000). En este caso, cada individuo presenta un perfil diferente expresado en Categoría I-Dominancia (> 67 pts.), Categoría II-Indecisión (entre 34 y 66 pts.) y Categoría III-Rechazo (<34 pts.). El perfil individual representa un corte de las habilidades, destrezas, conocimientos, hábitos, creencias, valores personales, en un determinado momento de desarrollo.

Cabe agregar que existe la relación entre el tipo de dominancia y la inclinación profesional u ocupacional (Chulvi et al. 2013). Se considera que la dominancia en el Cuadrante A lleva a las personas a escoger ocupaciones en matemática, química, biología, ingeniería, medicina y finanzas, así como presentar las capacidades en la in- 
vestigación científica. Los individuos con la dominancia en el Cuadrante B generalmente seleccionan ocupaciones relacionadas con la planificación, administración, contabilidad y gerencias. Los del cuadrante C tienen una gran vocación de servicio, que es la parte importante de los profesionales en educación, sociología, enfermería, atención social. Las personas que tienen dominancia en el cuadrante D se desenvuelvan exitosamente en arquitectura, arte, pintura, literatura, música, diseño gráfico y escultura.

Asimismo, la aplicación de diferentes instrumentos que miden la Dominancia Cerebral de Herrmann permite descubrir la dominancia de más de un cuadrante. Por ejemplo, la combinación de los cuadrantes A y B significa la dominancia de la parte izquierda del cerebro, y la dominancia de cuadrantes $\mathrm{C}$ y D corresponde al lado derecho. Si predominan los cuadrantes A y $D$, la persona tiene estilo de pensamiento Cerebral, y, en el caso de cuadrantes B y C, estilo de pensamiento Límbico. El estilo de pensamiento único de cada persona se desarrolla mediante una compleja interacción del potencial genético con todas las influencias externas, como ambiente sociocultural y aprendizaje (Gardié 2000).

Velásquez, Calle y Remolina (2006) describen la combinación de la dominancia de los cuadrantes resaltando los cuatro tipos de pensamiento siguientes:

a) Realista (del sentido común) formado por los cuadrantes A y B (hemisferio izquierdo);

b) Idealista (kinestésico) constituido por los cuadrantes C y D (hemisferio derecho);

c) Pragmático (cerebral) correspondiente los cuadrantes o áreas A y D (cortical); d) instintivo (visceral) formado por los cuadrantes B y C (sistema límbico).

En referencia a la clasificación anterior, Velásquez, Calle y Remolina (2006) y Gómez (2004) intentan detallar las competencias, comportamientos y procesos cognitivos característicos para cada cuadrante:

\section{A (Cortical Izquierdo)}

Comportamientos: es distante, frío, con pocos gestos y voz elaborada, intelectualmente brillante, capaz de criticar, competitivo, irónico, individualista, entre otros.

Procesos cognitivos: lógica, análisis, rigor, razonamiento, claridad; inclinación por los modelos y teorías, procede por hipótesis, colecciona hechos, prefiere la palabra precisa.

Competencias: cuantitativa; abstracción; finanzas; matemática; técnica; resolución de problemas.

\section{B (Límbico Izquierdo)}

Comportamientos: emotivo, introvertido, controlado, maniático, minucioso, tiende a monologo; inclinación por las fórmulas, conservador, defensa del espacio, fiel, amor al poder, vinculación a la experiencia.

Procesos cognitivos: formalización, planificación, estructura secuencial, verificador, definición de procedimientos, metódico y ritualista.

Competencias: sentido de organización, administración, realización y puesta en marcha; orador, liderazgo, trabajador consagrado.

\section{C (Límbico derecho)}

Comportamientos: espontáneo, extrovertido, gesticulador, emotivo, hablador, 
lúdico, aquiescente, espiritual, reacción fuerte contra las críticas negativas.

Procesos cognitivos: tendencia al principio del placer, integración mediante la experiencia, trabaja con base en sentimientos, fuerte implicación afectiva, siente la necesidad de compartir y de vivir en armonía, escucha y pregunta, evalúa los comportamientos.

Competencias: propensión al diálogo, relaciones interpersonales, tendencia a la enseñanza, competencias comunicativas, trabajo en equipo.

\section{D (Cortical Derecho)}

Comportamientos: inclinación por el riesgo, originalidad, tendencia a las discusiones, sentido del humor, futurista, espacialidad, independencia, discurso brillante. Procesos cognitivos: síntesis, conceptualización, imaginación, asociación, integración de imágenes y metáforas, visualización.

Competencias: visión de futuro, espíritu empresarial, innovación, creación, investigación.

Velásquez, Calle y Remolina (2006) refieren que, de acuerdo al modelo de cuadrantes cerebrales de Herrmann, la interacción docente-alumno se apoya en los siguientes estilos conductuales:

- El cortical izquierdo prioriza el contenido; el docente presenta las hipótesis enfatizando en las pruebas; y el estudiante prefiere las clases argumentadas basadas en los hechos.

- El límbico izquierdo se basa en la organización; el docente da mayor importancia a la forma que al fondo; y el estudiante requiere las clases desarrolladas según los parámetros establecidos y rutinarios.
- El límbico derecho busca la comunicación e interrelación; el docente se preocupa por la recepción de los conocimientos por el estudiante; mientras que el alumno es activo si el docente o el tema lo agrada, se frustra si no se valoran sus progresos.

- El cortical derecho tiene la visión de futuro a largo plazo; el docente avanza su clase globalmente, introduciendo los conceptos nuevos, y el estudiante es intuitivo, puede sorprender con conclusiones inesperadas y trabajos originales.

Respecto del proceso de aprendizaje y evaluación, los mismos autores resumen lo siguiente:

- El estudiante CI prefiere primero conocer la teoría, leyes y el funcionamiento previo a la experimentación. El docente CI prioriza el saber teórico, razonamiento abstracto y el espíritu crítico.

- El estudiante LI se siente cómodo en las clases bien estructuradas, rechaza la desorganización, improvisación, los errores, imprecisiones e inseguridad del profesor. El docente LI prioriza el saber al contenido, evalúa el orden en los trabajos y la disciplina del alumno.

- El estudiante LD tiene la necesidad de compartir lo aprendido e interactuar con sus compañeros. El profesor LD valora la actitud participativa, la integración con el grupo y esfuerzo aplicado.

- El estudiante CD busca la originalidad, novedad, improvisación, experimentación e intuición. El profesor CD evalúa al estudiante en forma global, le gustan los trabajos que demuestran originalidad e imaginación. 
En las Tablas 1 y 2 se sintetizan las ventajas y desventajas de diferentes tipos de pedagogía, y se proponen las estrategias propias del proceso de enseñanza-aprendizaje de acuerdo a las diferencias de las dominancias cerebrales. La teoría del Cerebro Total trata de unir diferentes enfoques para explicar el funcionamiento del cerebro humano.

TABLA 1

Ventajas y desventajas de los tipos de pedagogía

\section{Ventajas}

Desventajas

\section{CORTICAL IZQUIERDO}

Riguroso, fiable, preciso, claro, estable, pertinente, competente, profesional, creíble. Se apoya en los hechos (rechaza lo arbitrario). Da pruebas, analiza los procesos utilizados, avanza de forma lineal. Se expresa por escrito concisamente. Permite reproducir fácilmente los ejercicios. Directivo. Objetivo: se basa en hechos. De espíritu crítico. Exigente. Encuentra el placer intelectual y lo comunica. Utiliza bien el material. Conoce las referencias, las experiencias, los resultados: los demás se dirigen a él cuando no saben algo. Saben guardar distancia frente a las manifestaciones afectivas. Estimula a los alumnos mediante una sana competencia. Gana con el trato.
Seco, falto de contacto y de fantasía, despreciativo, suficiente, intolerante con las preguntas 'estúpidas' (y también cuando no comprende cómo funcionan los otros). Muy exigente. Lenguaje hermético. Abstracto. Muy directivo. Ironiza, critica, lanza indirectas. Se molesta por las intervenciones de tipo 'parásito' y por las digresiones. Se desestabiliza por las preguntas que no conoce. Bloquea la expresión espontánea. Destroza lo imaginario y la creatividad. Se interesa por los primeros de la clase. Provoca la pasividad en los otros. Selectivo, no saca a la pizarra a los flojos. Le cuesta trabajo entender que alguien no comprenda. No repite: cree que es evidente. No encuentra palabras para explicar algo de otra forma. No tiene en cuenta las exigencias de trabajo de otras disciplinas. Insiste en aprobar a un alumno porque es bueno, a pesar de las protestas de sus colegas. Gasta siempre las mismas bromas. No cambia casi nada.

\section{LÍMBICO IZQUIERDO}

Concienzudo (minucioso), puntual, prudente (con los proyectos aventurados). Metódico, cumplidor, objetivo (no tiene preferidos). Eficaz, seguro (con él se sabe a dónde se va). Tiene sangre fría, sabe dominarse. Capaz de controlarse. Crea ambientes tranquilizadores. Da seguridad. Pone 'parapetos' para evitar las caídas. Dirige su clase. Tiene pocos problemas de disciplina. Da normas para la vida. Termina su programa. Planifica su año escolar. Gestiona bien su tiempo. Da instrucciones claras. Presenta documentos pulcros. Comprueba los cuadernos o las agendas poniendo de manifiesto las omisiones. Realiza evaluaciones con regularidad. Organiza viajes y visitas, se encarga de la administración. Metido en su molde. Bien considerado por su eficacia, puntualidad y asiduidad. Toma posesión del territorio: personaliza y decora su clase.
Escolar. Da mucha importancia al horario. Rutinario (propone siempre las mismas elecciones). Quisquilloso en la presentación de trabajos y carpetas. Maniático, monótono, pesado. Regulador (le gustan las fórmulas). Autoritario, impone su forma de pensar: 'o se dobla o se rompe'. Falta de apertura. Violento, reconcentrado; aterroriza a algunos alumnos. Dirigente, despótico, Le gusta el poder y puede abusar de él. Conservador. No se entrega. No le gusta el cambio ni la innovación ni la sorpresa. Se desconcierta con la originalidad. Corta la inspiración. Bloquea la curiosidad de los alumnos. Provoca pasividad. Coloca etiquetas a los alumnos. Le gusta el papeleo. Defiende su territorio su clase, su armario, su aula. Toma ideas de los otros y las aplica. Le atraen poco las nuevas pedagogías. Trabaja en equipo si está de acuerdo con los métodos y si se es eficaz y puntual. $\mathrm{Ca}$ rece fundamentalmente de seguridad. 


\section{LÍMBICO DERECHO}

Cálido, humano, lúdico, entusiasta. Establece buenos contactos. Mediador, negociador, disponible. Escucha a los otros. Comprensivo, generoso, gratificante. Sabe apoyarse en las cualidades de los otros. Tiene sentido del diálogo. Hace que los alumnos se atrevan a hablar. Establece un clima de confianza. Favorece el entendimiento y la armonía en clase. Le gusta trabajar en equipo. Favorece la interdisciplinariedad. Sabe adaptarse al grupo-clase. Sabe presentar un trabajo difícil. Establece una pedagogía del estímulo. Recupera al 'calamidad'. Suscita vocaciones. Hace una evaluación más formativa que sumativa. Acepta ser desmitificado. Hace saber su estado de ánimo. Tiene estallidos saludables. Desdramatiza las situaciones.
Demasiado paternalista. Establece dependencia afectiva. Tiene preferidos y cabezas de turco. Susceptible. Versátil, inconstante, lunático. Se deja 'invadir' por los alumnos. Subjetivo, parcial. Pesado, invasor. Gesticula mucho, cansa. Inquisidor (quiere conocer la vida privada). Moralizador, charlatán, redundante. Farsante (comediante). Demagogo. Incapaz de expresar un rechazo. No se atreve a criticar. Seleccionado para el puesto de otros. No hace más que lo que le gusta. No termina sus clases (desbordado). Pierde el tiempo. Arrastra su programa. No soporta las clases silenciosas. Cuenta su vida. Demasiado camarada. Tiene berrinches. Provoca psicodramas. Interviene durante los exámenes (desconcentra a los alumnos). No puede reproducir la misma lección dos veces. Tiene demasiada preferencia por la evaluación oral. Hace más observaciones sobre el comportamiento que sobre los conocimientos.

\section{CORTICAL DERECHO}

Imaginativo, creativo, innovador. Lleno de ideas y proyectos. Propone novedades pedagógicas. Original, caprichoso (poco realista). Humor ácido. Estimulante. Con sentido artístico y estético, organiza sesiones de diapositivas y talleres. Globaliza y sintetiza. Va directo a lo esencial. Se fija objetivos a largo plazo. Abierto al mundo, favorece la apertura. Sobrepasa los límites de la clase. Trabaja sobre un tema en conexión con los profesores de disciplinas diferentes. Tiene chispa (pensamientos rápidos). Trabaja deprisa. Visionario: hace pronósticos buenos sobre el porvenir de un alumno. Renueva sus clases. Transmite las cosas con imágenes. Propone ejemplos concretos que se recuerdan. Posee el arte de dar rodeos. Favorece la experimentación en detrimento de la teoría. Crea una estructura flexible, un espacio de tolerancia. Puede cautivar a los alumnos. Impulsa las motivaciones para realizar investigaciones y abrirse al mundo: lecturas, excursiones, visitas. Termina su programa.
Perturbador. Desconcertante. Desorienta. Falta de rigor y análisis. Falta de plan y estructura. Se dispersa. Embarullado y desordenado. Falta de precisión. Falta de indicaciones para facilitar la comprensión. Salta de un tema a otro. Procede por asociación (no por sucesión de ideas). Se sale del tema. Hace digresiones. Da informaciones vagas e insuficientes. Demasiado general. Se aleja, se distrae. Pierde el sentido de lo concreto. Impone sus imágenes sin ligarlas con la noción que se quiere ilustrar. Ambiguo: expone una cosa y lo contrario de estasin dar una elección final. Produce inseguridad. No cuantifica la evaluación. Deja a los alumnos la responsabilidad de sí mismos. Deja que los alumnos estructuren el curso, se dirige a los más favorecidos (los que tienen ya una buena estructuración). Se le quiere o se le rechaza. Se le adora o se le detesta. Tiene proyectos muy ambiciosos. Corta la palabra a los alumnos en cuanto sabe qué preguntarán. Comprueba poco lo que han aprendido. 
TABLA 2

Estrategias pedagógicas a usar con alumnos de cada Cuadrante

ALUMNO CORTICAL IZQUIERDO

\section{Qué le falta a este alumno}

Es poco creativo. Le falta imaginación. Desarrolla mal sus ideas. Tiene pocas ideas personales y no expresa su sensibilidad. Tiene pocas aptitudes para el arte. Tiene problemas con las materias literarias: expresión seca, sin emociones. Es demasiado individualista.

\section{Qué hacer con este alumno}

Utilizar con él una pedagogía racional que dé prioridad al contenido: utilizar el libro o el manual. Terminar el programa. Proporcionar hechos. Insistir en la teoría. Dar definiciones precisas. Dar referencias. Mostrar esquemas abstractos: diagramas, curvas. Dar cifras y estadísticas. Trabajar en informática. Partir de la hipótesis, de la ley, para llegar a la experimentación (deducción). Procurar que haga ejercicios en progresión, yendo de lo más sencillo a lo más difícil, para estimular su espíritu de competición.

\section{Cómo procurar que se abra a otros cuadrantes}

Utilizar su gusto por la competición: cualquier idea nueva será tomada en cuenta y aumentará su nota. Hacer que prepare trabajos orales. Hacerle intervenir ante toda la clase. Transformar los símbolos en imágenes y metáforas. Enseñarle a ver las cosas en su globalidad. Practicar juegos que le ayuden a desarrollar su sentido espacial. Hacer que proponga sus ideas desorganizadamente antes de organizarlas. Organizar actividades de reflexiones dirigidas, asociando en ellas ideas con imágenes. Hacer que describa una situación con los cinco sentidos. Hacer poesía. Imaginar y crear mediante la mímica y el dibujo. Hacer que conozca el mundo por medio de visitas escolares para desarrollar su sensibilidad artística.

\section{ALUMNO LÍMBICO IZQUIERDO}

\author{
Qué le falta a este alumno
}

Le falta apertura, fantasía y visión global. No sabe qué hacer frente a un imprevisto. Le resulta difícil trabajar con medios audiovisuales. No sabe resumir un texto o una situación.

\section{Qué hacer con este alumno}

Utilizar con él una pedagogía organizada, estructurada en un clima de seguridad: escribir la programación en la pizarra en forma clara y legible. Darle instrucciones estrictas. Proporcionarle documentos escritos impecables. Dividir la hora de clase en secuencias, indicándolo previamente. Proponerle objetivos a corto plazo bien definidos. Permitirle salirse de las normas para pasar a la experimentación (le gustan los trabajos manuales y tiene éxito en ello). Es preciso que conozca las relaciones con lo que conoce. Es necesario respetar su territorio: no excitarle pidiéndole algo bruscamente.

\section{Cómo procurar que se abra a otros cuadrantes}

Elogiarle cuando tiene éxito en algo. Darle confianza en sí mismo. Utilizar su faceta de líder y dirigente para una buena causa. Hacer fichas de evaluación donde perciba lo que sabe hacer y sus progresos. Desarrollar su memoria dándole reglas mnemotécnicas. Enseñarle a exteriorizar y a comunicar haciendo exposiciones en tiempos delimitados y breves. Proporcionarle modelos para que se lance a ejercicios nuevos. Enseñarle a resumir las clases: tres palabras clave y basta dos o tres puntos concretos. Enseñarle a globalizar: leer un texto, dividirlo en varias partes y darle títulos; inventar un título global a partir de esos títulos secundarios. Utilizar su sentido de la organización. 
ALUMNO LÍMBICO DERECHO

Qué le falta este alumno

Le falta orden, rigor, conocimientos precisos. Le falta saber escuchar (aunque sabe hacerlo si consigue dominarse). Le falta control y dominio de sí mismo, organización, y tiene poca autonomía y perspectiva frente a la opinión de otros.

\section{Qué hacer con este alumno}

Proporcionarle una pedagogía emotiva y concreta: crear un ambiente cálido y acogedor. Establecer un diálogo eficaz (no constante). Elogiar sus progresos, sus actitudes positivas. Partir de sus vivencias (su experiencia): lo que es, lo que hace, lo que sabe, lo que le gusta. Realizar gestos eficaces: con frecuencia el LD es un cenestésico. Dejar que decore su cuaderno, sus deberes, que personalice sus trabajos. Favorecer los trabajos en grupo canalizando las charlas sobre problemas personales. Variar los ejercicios. Jugar, moverse, aprender divirtiéndose: juegos, visitas, teatros, música. Partir de imágenes y representaciones personales hasta llegar a la abstracción. Darle responsabilidades y confiarle funciones de comunicación y negociación.

\section{Cómo procurar que se abra a otros cuadrantes}

Ayudarle a organizarse, comenzar por el mantenimiento del cuaderno de programación. Ayudarle a buscar el sentido preciso de las palabras, tener un diccionario en la clase. Leer los textos en voz alta aceptando preguntas para asegurar la comprensión. Sustituir los 'me gusta, no me gusta' por los 'sé, no sé'. Proporcionar métodos y comenzar por lo que sabe, para darle confianza y ponerle en condiciones de tener éxito. Canalizar su espontaneidad y su impulsividad diciéndole que, antes de intervenir, 'hable para sus adentros' para clasificar, escoger y organizar sus ideas. Enseñarle a dominar sus emociones y a hablar de ellas. Enseñarle a suprimir el 'yo' y a utilizar el 'él', es decir a tomar perspectiva respecto a sus afectos (establecer diferencia entre autor y narrador). Actuar como "abogado del diablo" para crear la distancia entre el 'yo' y 'el otro': pros y contras. Procurar que se haga teatro de improvisación (ateniéndose a unas reglas rigurosas que se imponen) para obligarle a ceñirse a una ley impuesta. Utilizar sus habilidades de negociador y sus dotes para el contacto humano, para convertirle en delegado de la clase.
ALUMNO CORTICAL DERECHO

\author{
Qué le falta este alumno
}

Le falta organización, estructura, espíritu de grupo, claridad (pasa de una idea a otra), rigor, lógica y método.

\section{Qué hacer con este alumno}

Proporcionarle una pedagogía imprevisible, original, imaginativa y concreta: proponer ejemplos concretos y visibles. Utilizar soportes visuales. Tener humor. Utilizar el método experimental y empírico. Proponer clases variadas, ricas, con interrupciones gráficas concretas. Permitirle ensayar con riesgo de equivocarse. Proponer juegos, obras imaginativas, teatro. Darle la posibilidad de hablar, decir aberraciones, tener ideas incongruentes al margen de las lecciones. Darle ocasión de inventar, crear, innovar sin presión.

Cómo procurar que se abra a otros cuadrantes

Ayudarle a clasificar sus ideas, a ir más allá de sus adquisiciones. Enseñarle rigor y método a partir de diagramas que favorezcan la organización planificada de elementos o ideas lanzados en desorden. Cuando tenga que reflexionar sobre el contenido de una tarea, se le aconsejará que escriba todas sus ideas tal como se le ocurran en un papel y que después las estructure, jerarquizando las respuestas y los argumentos. Pedirle que justifique sus respuestas. Desarrollar una idea justificando las etapas mencionadas. Reconstruir el camino del pensamiento que ha llevado a una respuesta espontánea. Ponerle trampas para que perciba los riesgos de la intuición pura, sin comprobación. Hacerle encontrar un enunciado a partir de un resultado. Pedirle que reconstruya el principio de un texto a partir de una conclusión. Hacer que complete un rompecabezas en tiempo limitado. Hacerle que responda a una norma dada.

Fuente: Ojeda-Hidalgo y Díaz-Acevedo (2010), Velásquez, Calle y Remolina (2006), Gómez (2004) 


\section{CONCLUSIONES}

Los modelos educativos del nuevo milenio deben considerar los resultados de los descubrimientos neurocientíficos. Si pretendemos modificar el cerebro del educando para hacerlo más eficiente y adaptado, tenemos que tener en cuenta su estructura y funcionamiento durante la elaboración y aplicación de las estrategias para el proceso de enseñanza-aprendizaje.

Mediante los conocimientos provenientes de las investigaciones neurocientíficas será posible desarrollar las capacidades cognitivas de las personas, implementar el aprendizaje significativo, desarrollar el pensamiento crítico y abstracto, elevar la autoestima y construir los valores.

La Neurociencia contribuye a comprender los procesos cerebrales y sus manifestaciones conductuales desde diversas perspectivas. El cerebro es un órgano dividido en partes e integrado en un todo al mismo tiempo, y solo desde este enfoque podemos comprender la conducta humana e influir sobre ella de una manera óptima.

La teoría del Cerebro Total sistematiza e integra las apreciaciones anteriores; asimismo, existen instrumentos de evaluación que permiten realizar un diagnóstico y determinar los estilos de pensamiento de los estudiantes.

Cabe agregar que para mejorar la calidad del proceso educativo no basta solo con determinar la forma cómo aprenden los alumnos, sino que el docente conozca también los distintos procesos de aprendizaje $y$, de esta manera, diversifique el estilo de enseñanza.
Por las consideraciones anteriores, el docente puede disponer de descubrimientos neurocientíficos para mejorar su comprensión del proceso de aprendizaje, perfeccionar sus capacidades de enseñanza mediante nuevas estrategias, y abandonar las prácticas inadecuadas, antieducativas y tradicionales que hasta ahora afectan al sistema educativo.

Asimismo, la constante actualización de los conocimientos hace poco útil la simple trasmisión de los contenidos teóricos inertes, y obliga al profesor a considerar otros aspectos del proceso educativo, como empatía, ambientes agradables, calor humano y armonía en la relación con los alumnos, sin perder el principio de autoridad y rol de guía.

\section{REFERENCIAS BIBLIOGRÁFICAS}

Castro, R. (2012). David Jou: "No hay duda de que es más complejo el cerebro que el universo". Aragón investiga. Disponible en: <http://www.aragoninvestiga.org/david-jou-no-hay-duda-deque-es-mas-complejo-el-universo-interior/\#>.

Chulvi, V., Felip, F., García, C., Galán, S. y Mulet, E. (2013). ¿Existe correlación entre los perfiles de los estudiantes y la elección de su especialidad? Ponencia presentada en el 17th International Congress on Project Management and Engineering, Logroño.

De Aparicio, X. (2009). Neurociencias y la transdisciplinariedad en la educación. Revista Universitaria de Investigación y Diálogo Académico, 5(2), 1-21.

De la Barrera, M. y Donolo, D. (2009). Neurociencias y su importancia en con- 
textos de aprendizaje. Revista Digital Universitaria, 10(4), 1-18. Disponible en: <http://www.revista.unam. $\mathrm{mx} /$ vol.10/num4/art20/art20.pdf>.

Francis, S. (2005). El aporte de la neurociencia para la formación docente. Actualidades Investigativas en Educación, 5(1), 1-19. Consulta: 14 junio, 2018. Disponible en: <http://revista. inie.ucr.ac.cr/ediciones/controlador/ Article/accion/show/articulo/el-aporte-de-la-neurociencia-para-la-formacion-docente.html>.

Gardié, O. (2000). Determinación del perfil de estilos de pensamiento y análisis de sus posibles implicaciones en el desempeño de profesionales universitarios venezolanos. Estudios Pedagógicos, 26, 25-38.

Gómez, J. (2004). Neurociencia Cognitiva y Educación. Chiclayo: Fondo Editorial FACHSE.

Maureira, F. (2010). Neurociencia y educación. Exemplum, 3, 267-274.

Ministerio de Educación (2006). Guía para el desarrollo del Pensamiento Crítico.
Consulta: 14 de junio, 2018. Disponible en: <https://es.slideshare.net/ centropoblado3/gua-para-el-desarrollo-del-pensamiento-crtico-minedu>.

Ojeda-Hidalgo, J. y Díaz-Acevedo, N. (2010). Caracterización de los estilos de pensamiento de los alumnos de una carrera de perfil administrativo en una universidad pública de la Región Laja-Bajío, bajo la perspectiva de la teoría HBID. Pistas Educativas, 94, 81-97.

Salas, S. (2003). ¿La educación necesita realmente de la Neurociencia? Estudios Pedagógicos, 29, 155-171.

Unesco (2010). Informe Mundial sobre el Aprendizaje y la Educación de Adultos. Consulta: 24 de agosto, 2018. Disponible en: <http://uil.unesco. org/fileadmin/keydocuments/AdultEducation/es/GRALE_spanisch.pdf $>$.

Velásquez, B., Calle, M. y Remolina, N (2006). Teorías neurocientíficas del aprendizaje y su implicación en la construcción de conocimiento de los estudiantes universitarios. Tabula Rasa, 5, 229-245. 